\title{
Correction to: Self-insurance and saving under a two- argument utility framework
}

\author{
Jimin Hong ${ }^{1} \cdot{\text { Kyungsun } \mathrm{Kim}^{2}}^{2}$ \\ Published online: 16 June 2021 \\ (c) Springer-Verlag GmbH Austria, part of Springer Nature 2021
}

\section{Correction to: Journal of Economics https://doi.org/10.1007/s00712-021-00738-8}

The original article has been corrected.

In the original publication of the article, there is a typo in Proposition 3 (3) (ii). The right version should read as follows.

Proposition 3 (3) The effects of an increase in initial health on self-insurance and saving are as follows.

(i) An increase in initial health reduces self-insurance and raises saving if:

(a) $\quad u_{C A}>0, \frac{u_{C C}\left(y_{0}-f(e)-s, h\right)}{u_{C}\left(y_{0}-f(e)-s, h\right)}+R \frac{u_{C A}\left(y_{1}+R s, h-l(e)\right)}{u_{A}\left(y_{1}+R s, h-l(e)\right)}<0, \quad$ and $\quad-\frac{u_{C A}\left(y_{0}-f(e)-s, h\right)}{u_{C}\left(y_{0}-f(e)-s, h\right)}$ $>-\frac{E u_{C A}\left(y_{1}+R s, \tilde{h}\right)}{E u_{C}\left(y_{1}+R s, \tilde{h}\right)}$ or,

(b) $\quad u_{C A}<0$, and ACA in $A$ at time 0 is greater than ACA in $A$ at time 1 and less than ARA in $A$ in the loss ate at time 1 . That is, $u_{C A}<0$ and $-\frac{E u_{C A}\left(y_{1}+R s, \hat{h}\right)}{E u_{C}\left(y_{1}+R s, \hat{h}\right)}<-\frac{u_{C A}\left(y_{0}-f(e)-s, h\right)}{u_{C}\left(y_{0}-f(e)-s, h\right)}<-\frac{u_{A A}\left(y_{1}+R s, h-l(e)\right)}{u_{A}\left(y_{1}+R s, h-l(e)\right)}$.

The original article can be found online at https://doi.org/10.1007/s00712-021-00738-8.

Kyungsun Kim

sunny2030@snu.ac.kr

Jimin Hong

jmhong@ssu.ac.kr

1 Department of Statistics and Actuarial Science, Soongsil University, 369 Sangdo-Ro, DongjakGu, Seoul 06978, Korea

2 Institute of Finance and Banking, Seoul National University Business School, 1 Gwanak-Ro, Gwanak-Gu, Seoul 08826, Korea 
(ii) An increase in initial health reduces both self-insurance and saving if $u_{C A}>0, \quad \frac{u_{C C}\left(y_{0}-f(e)-s, h\right)}{u_{C}\left(y_{0}-f(e)-s, h\right)}+R \frac{u_{C A}\left(y_{1}+R s, h-l(e)\right)}{u_{A}\left(y_{1}+R s, h-l(e)\right)}>0, \quad$ and $\quad-\frac{u_{C A}\left(y_{0}-f(e)-s, h\right)}{u_{C}\left(y_{0}-f(e)-s, h\right)}<-$ $\frac{E u_{C A}\left(y_{1}+R s, \tilde{h}\right)}{E u_{C}\left(y_{1}+R s, \tilde{h}\right)}$.

See the Appendix and the text above.

(i) An increase in initial health reduces self-insurance and raises saving if , $u_{C A}<0, \frac{u_{C C}\left(y_{0}-f(e)-s, h\right)}{u_{C}\left(y_{0}-f(e)-s, h\right)}+R \frac{u_{C A}\left(y_{1}+R s, h-l(e)\right)}{u_{A}\left(y_{1}+R s, h-l(e)\right)}>0, \quad$ and $\quad-\frac{u_{C A}\left(y_{0}-f(e)-s, h\right)}{u_{C}\left(y_{0}-f(e)-s, h\right)}<-$ $\frac{E u_{C A}\left(y_{1}+R s, \hat{h}\right)}{E u_{C}\left(y_{1}+R s, \hat{h}\right)}$.

Publisher's Note Springer Nature remains neutral with regard to jurisdictional claims in published maps and institutional affiliations. 